\title{
AN EXPERIMENTAL STUDY ON ALTERNATIVE CFRP RETROFITTING APPLICATIONS OF HERITAGE STRUCTURES
}

\author{
N. TORUNBALCI, E. ONAR \& F. SUTCU \\ Faculty of Architecture, Istanbul Technical University, Istanbul, Turkey.
}

\begin{abstract}
It is crucial for masonry structures of historical value to increase their seismic performances in order to be protected against earthquakes. The damages to the masonry structures might be attributed to insufficient soil properties, non-conformity with relevant regulations, design and application defects and wear. This study experimentally investigates the strengthening of the masonry structures on one side as historical structural walls can only be strengthened on one side in most cases. In the experimental works conducted within the scope of the study, the brick wall specimens, some of which are pre-damaged, are strengthened on one side using carbon fibre reinforced polymers (CFRPs) in different forms. Comparisons are made between the change in the load-bearing capacities and behaviours of the specimens following the strengthening. It is determined that the brick wall specimens without reinforcement exhibit brittle behaviour, whereas the performances of the brick wall specimens strengthened with CFRP improve in strength ratings as well as energy dissipation capacities. The improvements in the specimens of the structural brick walls become much more outstanding when the strengthening is applied on the overall surface of the wall in textile form rather than in strip form.

Keywords: masonry structures, strengthening heritage structures, fiber reinforced polymers.
\end{abstract}

\section{INTRODUCTION}

The majority of buildings in Turkey are masonry structures and the masonry walls are mostly made of bricks. In addition to numerous structures of monumental and historical value, the majority of the structures constructed both in the rural and urban areas are of the masonry structure type. Although masonry brick walls are known to have high vertical load-bearing capacity, they are weak for lateral loading such as earthquakes. Strengthening should be provided for the structures to maintain the structural integrity, which may not have been taken into consideration during the original design or construction, to increase their load-bearing capacities as a result of the change in their functional usage, to eliminate the defects attributed to incorrect or insufficient application during construction and to supplement the load-bearing capacities that may be reduced as a result of wear in the course of time. Considering the fact that our country is in a risk region in terms of earthquakes, it is essential to strengthen the structural masonry walls.

Strengthening by shotcrete on the surface of the walls coated with a steel mesh reinforcement is a popular method. However, shotcrete application is not free of any further problems in practice as the application pressure might cause major damage to a historical masonry wall. Where conventional concrete is used, however, placing and compacting the concrete prove to be difficult due to the insufficient size of the formwork. Increasing the thickness of the concrete layer can eliminate the problem, but, this in turn, gives rise to undesirable loss of footing area. This type of strengthening is therefore not preferred, even if it greatly contributes to the structural performance. Where self-compacting concrete is used, the majority of the aforementioned problems are eliminated; however, this time the original architecture of the structure is jeopardized. Another method still under investigation involves the strengthening of existing structural walls using fibre-reinforced polymer (FRP) materials. Especially for historical structures, FRP strengthening can be used on one side of the walls and covering the surface with a thin layer of the original stone or brick is still an option to keep the authentic look. 
Providing a practical and efficient solution where the use of the concrete and steel materials proves to be difficult, FRP strengthening materials obtained by mixing carbon, glass and aramide with the reinforced resin provide higher tensile strength than steel due to its fine, corrosive resistant and durable fibrous structure. Application while the structure is in use is also possible. Available in stripe/ laminated or textile form, FRP is applied on the wall surface with an epoxy adhesive. The fibres take up the loading, while the epoxy adhesive ensures homogenous load distribution between the fibres, protecting them from environmental effects. The FRP method might effectively be used in strengthening structures of historical value due to its potential for preserving original architecture of the structures to a great extent.

Various experimental and analytical studies have been performed on the behaviour of the structural masonry walls under in-plane, out-of-plane and axial loading. In a study undertaken by Ehsani et al. [1], the investigation is performed on the behaviour of the structural walls subject to loading acting out of the loading plane of the walls that are strengthened with carbon fibre reinforced polymer (CFRP) materials as stripes placed in orthogonal directions to the joints on both surfaces. The study determines that CFRP stripe materials prove to be a good alternative for strengthening the structural brick walls against the lateral loads in that energy dissipation capacities are improved. Albert et al. [2] conducted experimental works to determine the behaviour of the structural brick walls strengthened using carbon and glass FRPs under cyclic axial compressive loading, with various FRP forms, quantities and number of layers. Also providing the analyses on out-of-plane lateral loading, the study establishes that the performance of pre-damaged and non-damaged brick wall specimens strengthened using carbon fibre stripes are much better than those strengthened using glass fibres. Tan et al. [3] in their work strengthen the brick wall specimens using FRP under three different anchoring methods. For strengthening, they used specimens of $1000 \mathrm{~mm} \times 1000 \mathrm{~mm} \times 110 \mathrm{~mm}$ size. The results of the experiments prove that the increase in out-of-plane strengths of the retrofitted brick wall specimens is significant. Fractures are observed in the brick wall specimens without reinforcement due to bending, whereas retrofitted ones underwent four different failure modes, namely, the shear failure along the bricks, weakening of the bond between the FRP and the brick wall surfaces, formation of bending cracks and formation of tensional failure of FRP strengthening materials. In a study where 42 wall specimens subject to in-plane loading with the angle between the horizontal joints and axial force being $0^{\circ}, 30^{\circ}, 45^{\circ}, 60^{\circ}$ and $90^{\circ}$ reinforced by laminated glass FRP [4], it is determined that FRP has a significant influence on increasing the strength and failure mode as well as extension of the rigidity of the wall. They also determine that, compared with specimens without reinforcement, the compressive strength is increased by 160-500\%. Krevaikas et al. [5] conduct a study where 42 brick wall specimens are reinforced with one, two and three layers of CFRP stripes and five layers of GFRP and their behaviours are investigated under axial loading. It is determined, upon the experiment, that the load-bearing capacities and strains of the brick wall specimens are considerably increased. In a study performed by ElGawady et al. [6] on the static cyclic response of masonry walls retrofitted with FRP material, seven specimens are strengthened on one side. Results showed that the lateral displacement capacity increased by up to $490 \%$.

\section{PURPOSE OF EXPERIMENTAL WORKS AND TEST PLAN}

In this study, conventional brick walls are strengthened using laminated and textile CFRP materials on one side and the target was to determine the effect of this strengthening on the behaviours and the strength of the walls with an experimental approach. The brick wall samples were mounted on the testing rig in such a way so that the bed joints formed an angle of $45^{\circ}$ with the direction of vertical loading. Loading is exerted onto the concrete shoes constructed on opposing corners of the brick masonry specimens [7]. Half of the specimens were pre-damaged and repaired with epoxy resin 
before CFRP strengthening and the comparisons were made for the change in the load-bearing capacities and behaviours following the strengthening. Within the scope of this study, the aim was to also provide a comparative analysis on the effects of the form and quantity of CFRP and inspection of the displacements and failure modes, for which relevant specimen series were formed to correspond the resulting alternatives to the respective parameters.

The experiments consisted of three series with six brick wall specimens of size $185 \mathrm{~mm} \times 185 \mathrm{~mm} \times$ $45 \mathrm{~mm}$ provided for each series. Six brick wall specimens were used without strengthening as an additional series to represent unreinforced masonry (URM) walls. Displacements are measured by a transducer placed at $100 \mathrm{~mm}$ nominal length as shown in Fig. 1.

Half of each series is subjected to a pre-damaging process almost up to the level of the collapse. These damaged specimens are then repaired with epoxy resin. The compressive strength of the epoxy resin used for repair is $75 \mathrm{MPa}$ (7 days). Together with non-damaged specimens, these predamaged and epoxy-repaired specimens are then loaded until the occurrence of the failure in three different strengthening series. The behaviour of the damaged specimens is expected to be different from that of the non-damaged specimens. The target here is to see the effects of CFRP strengthening in both cases.

In Series I, ready-made $25 \mathrm{~mm}$ wide laminated CFRP strips are applied first in the direction of the tensile stresses and then compressive stresses of brick wall specimens (Fig. 2a).

In Series II brick wall specimens, the laminated CFRP strips are again applied first in the direction of the tensile stresses and then compressive stresses of brick wall specimens. For this case, however, $0.5 \mathrm{~cm}$ wide CFRP strips are used at a distance of $1 \mathrm{~cm}$ on both sides of CFRP strips of $1.5 \mathrm{~cm}$ width to provide a further spread reinforcement effect on a wider wall surface and is referred to as 'apartstrip FRP' in the study. The purpose here is to cover a wider surface with the same quantity of the strengthening material compared to Series I (Fig. 2b).

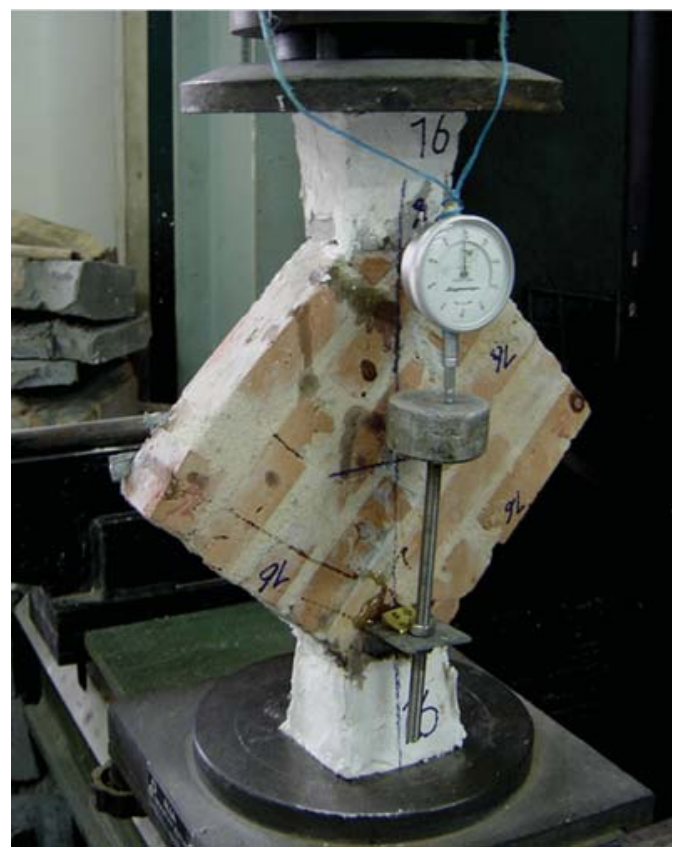

Figure 1: Brick wall specimens and test set up. 

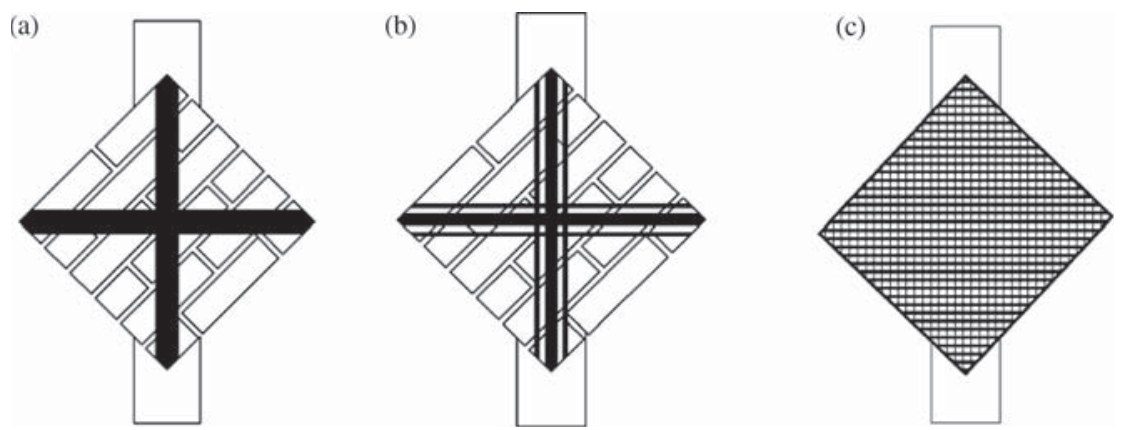

Figure 2: Strengthening types: (a) Series I - CFRP stripe, (b) Series II - CFRP apart-stripe and (c) Series III - CFRP textile.

Table 1: CFRP material and adhesive properties.

\begin{tabular}{lclc}
\hline Parameter & Details & \multicolumn{1}{c}{ Parameter } & Details \\
\hline CFRP stripe & & Stripe adhesive & \\
Tensile ultimate strength $(\mathrm{MPa})$ & 3,000 & Compressive strength (MPa) & 6 \\
Elongation at break, $\varepsilon_{\mathrm{u}}(\%)$ & 1.8 & Textile adhesive & \\
Tensile modulus $(\mathrm{MPa})$ & 165,000 & Tensile strength $(\mathrm{MPa})$ & 50 \\
Thickness of layer $(\mathrm{mm})$ & 1.2 & Compressive strength $(\mathrm{MPa})$ & 80 \\
$C F R P$ textile & & Tensile modulus $(\mathrm{MPa})$ & 3,000 \\
Tensile ultimate strength $(\mathrm{MPa})$ & 3,430 & & \\
Elongation at break, $\varepsilon_{\mathrm{u}}(\%)$ & 1.5 & & \\
Tensile modulus $(\mathrm{MPa})$ & 230,000 & & \\
\hline
\end{tabular}

For Series III, however, a $165 \mu \mathrm{m}$ thick unidirectional fabric sheet, namely textile CFRP is used. The textile CFRP is a cheaper material than the laminated CFRP and, therefore, the application of textile CFRP is performed in order to keep all the cracks to be formed on the surfaces of the brick wall specimens under control (Fig. 2c).

Plain brick wall specimens without pre-loading are nominated as URM, whereas brick wall specimens that are damaged and repaired by the epoxy material are nominated as damaged-epoxy retrofitted (D-ER). The nomination of the CFRP strengthened specimens in a series is as follows: damaged (D), stands for pre-damaged brick wall specimens; strip (S), for CFRP in the strip form; apart-strip (AS), for CFRP in the apart-strip form; and textile (T), for CFRP in the textile form. Accordingly, D-S stands for the pre-damaged brick wall specimens strengthened by CFRP strip on one side. Likewise, ND-T stands for the non-damaged brick walls strengthened with textile CFRP on one side.

\subsection{CFRP and brick wall properties}

Two types of CFRP material, namely stripe and textile CFRP, were used to strengthen brick wall specimens. Stripe CFRP is in laminated form of $1.2 \mathrm{~mm}$ thickness and the unidirectional textile CFRP has $165 \mu \mathrm{m}$ thickness. CFRP was applied on the specimen surfaces with their own adhesives. The two-part epoxy resin adhesives were prepared according to the volumetric proportion by the manufacturer. CFRP material and adhesive properties are given in Table 1. 
In constructing the brick wall specimens, the mortar is used in the cement:sand:water mixture ratio of 1:3.5:0.70. The mortar's compressive strength is $15.63 \mathrm{MPa}$, whereas the compressive strength of clay bricks reduced in size so as to construct the brick wall specimens is $18.92 \mathrm{MPa}$. The bricks are solid with no hollow. A joint size of $0.5 \mathrm{~cm}$ is adopted in constructing the brick wall specimens.

\section{RESULTS OF EXPERIMENTS}

In the course of determining in particular the behaviours of the brick wall specimens, three URM specimens are pre-damaged under axial compression and the cracks on the pre-damaged walls are repaired by epoxy materials and subject to further loading. The maximum stress sustained by the specimens is calculated from eqn (1) in accordance with American Society for Testing and Materials standards [8]:

$$
S_{S}=\frac{0.707 P}{A_{n}}
$$

where $S_{s}$ is the shear stress based on the net area, $P$ is the applied load and $A_{\mathrm{n}}$ is the area of the specimen calculated as in eqn (2):

$$
A_{n}=\left(\frac{w+h}{2}\right) t n
$$

where $w, h$ and $t$ are the specimen width, height and thickness, respectively, and $n$ is the percentage of the area of the unit that is solid, as a decimal. Average maximum strengths of the URM walls subject to loading and after repair by the epoxy materials following pre-damaging are determined as 0.79 and $1.22 \mathrm{MPa}$, respectively. Results are shown in Table 2, where COV represents the coefficient of variation. It was found that the displacements of the URM walls are increased twice as much following the epoxy repair. The shear stress-shear strain diagram for URM walls is illustrated in Fig. 3.

The failures in URM walls are in general along the joints of the walls. The fracture initiated along the bed joints propagates through the head joints, whereas the shear failures turn out to be the ultimate failure mode of the walls. In some cases, the fractures initiated at a joint propagated by breaking the bricks or the fractures initiated in the bricks propagated along the joints. The fractures in brick wall specimens repaired upon pre-damaging appear to be at different parts of the walls, rather than along the previous cracks repaired.

Table 2: General experimental results for unstrengthened wall specimens.

\begin{tabular}{lccccc}
\hline & & \multicolumn{3}{c}{ Maximum strength } \\
\cline { 3 - 6 } & & Test number & Test result (MPa) & Average (MPa) & COV (\%) \\
\hline Non-damaged & URM & 1 & 0.76 & 0.79 & 6.2 \\
& & 2 & 0.85 & & \\
Damaged & & 3 & 0.76 & & \multirow{2}{*}{ D-ER } \\
& & 1 & 0.76 & & \\
& & 3 & 1.44 & & \\
& & 3 & 1.44 & & \\
\hline
\end{tabular}




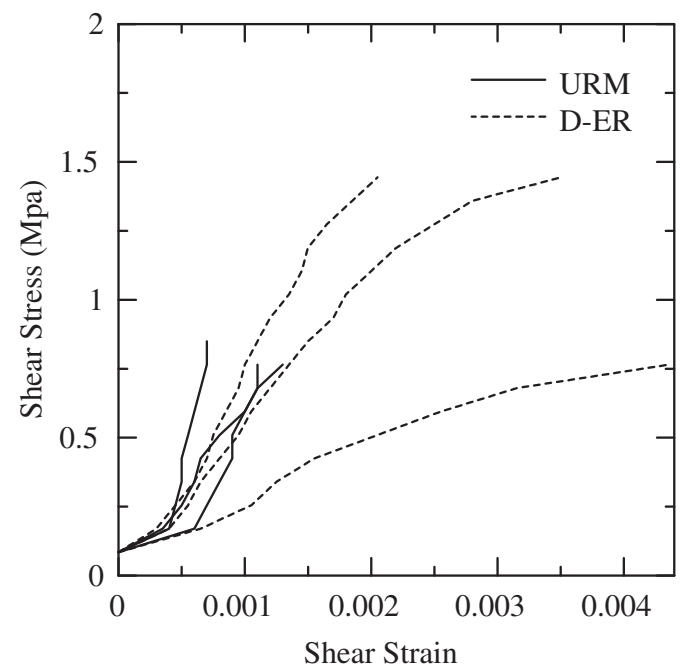

Figure 3: Shear stress-shear strain relation of unreinforced and repaired wall specimens.

Table 3: General experimental results for Series I.

\begin{tabular}{lccccc}
\hline & & \multicolumn{3}{c}{ Maximum strength } \\
\cline { 3 - 6 } & & Test number & Test result (MPa) & Average (MPa) & COV (\%) \\
\hline Damaged & D-S & 1 & 1.57 & 1.87 & 13.8 \\
& & 2 & 2.00 & & \\
Non-damaged & ND-S & 1 & 2.04 & & \\
& & 2 & 1.44 & 1.59 & 15.5 \\
& & 3 & 1.87 & & \\
& & & 1.44 & & 6.2 \\
& URM & & & 1.22 & 32.2 \\
\hline
\end{tabular}

\subsection{Evaluation of Series I specimens}

Series I consisted of six brick wall specimens strengthened with CFRP stripes on one side. Table 3 provides the experimental data on the maximum strength of the brick wall specimens.

Compared with URM brick walls, the strengthening of brick wall specimens classified under Series I significantly increases the strengths of the specimens. Furthermore, the increases in the degrees of the displacement are also significant compared to that of URM specimens (Fig. 4).

For Series I specimens, the sample types exhibiting the highest failure ratings are D-S, whereas the specimen types featuring lowest failure ratings are ND-S. Based on the comparisons, it can be concluded that strengthening of the walls on one side significantly improves their performances, irrespective of whether they are pre-damaged or non-damaged. The typical failure mode of the specimens is illustrated in Fig. 5.

It is determined that the strengths of the specimens increase almost $100 \%$ compared with that of the URM walls. It is interesting to observe that pre-damaged specimens show better performance 


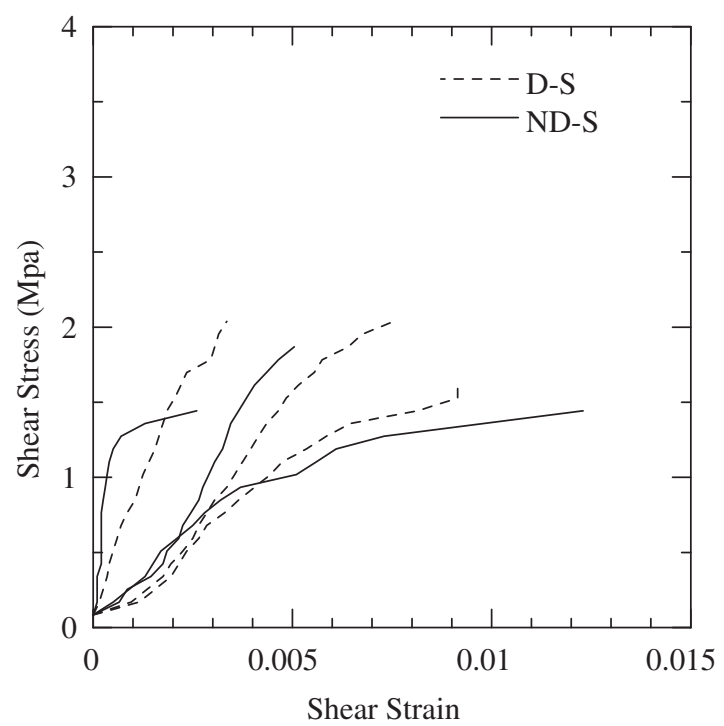

Figure 4: Series I shear stress-shear versus strain relation.

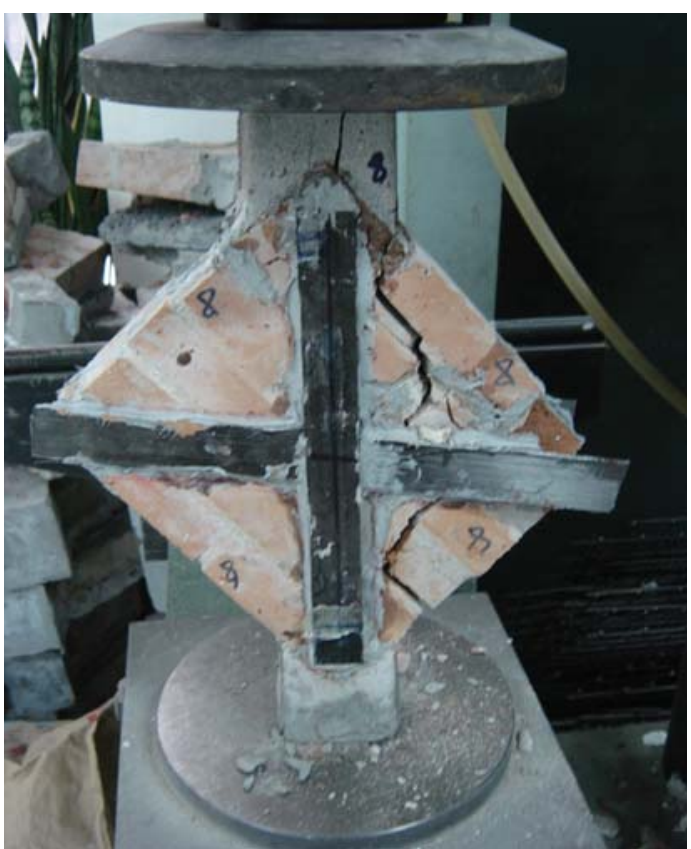

Figure 5: Series I failure mode.

than non-damaged ones. This is probably attributable to the effect of the epoxy materials used to repair the pre-damaged specimens. The URM brick masonry wall specimens undergo the damage along their weakest portion when pre-loading to induce the damage. Repair of these cracks generally performed along the compression diagonal of brick wall specimens, however, ends up with significant 
increases in the strengths of these portions compared to the other portion of the specimens. Therefore, this process provides significant improvements in both failure and strain characteristics of the walls.

Prior to failure, the cracks propagate along the portion of the brick wall specimens where no strengthening is provided. In some cases, the separations are observed between FRP strips and the surface of the specimens. Complete separation is, however, not observed in any one of the specimens. Notwithstanding the occasional cases where the URM brick walls undergo instantaneous failures under ultimate loading, no fragmentation is observed for the specimens strengthened with CFRP strips.

\subsection{Evaluations of Series II specimens}

Series II consisted of six brick wall specimens strengthened with CFRP apart-stripes. Table 4 provides the experimental data on the fracture loading of the brick wall specimens and provides a comparison of the average strength of Series II specimens to that of URM and D-ER specimens as well.

The specimens in Series II featuring the highest failure loading rating are DS-AS, whereas the lowest failure loading rating is observed for ND-AS. Irrespective of whether pre-damaged or nondamaged, the strengths of the URM brick walls are increased by 2.0-2.5 times following strengthening on one side. Compared with those in Series I, strength increases in Series II specimens imply that application of CFRP in the apart-stripe form is more advantageous.

The failure mode of the brick wall specimen is as illustrated in Fig. 6. Similar to the case for Series I specimens, no crack formation is observed in the portion of the specimens in Series II with CFRP, except the de-bonding between CFRP and wall surfaces in some cases. The stress-strain diagram is illustrated in Fig. 7, which provides information on the changes in the ductile behaviour of the specimens after strengthening.

\subsection{Evaluations of Series III specimens}

Series III specimens are provided with unidirectional fibre sheet CFRP strengthening in the tensional directions of the fibre axes. CFRP strengthening covers the entire surface of non-damaged and pre-damaged specimens on one side. Table 5 provides the experimental data on the maximum compressive strength of the specimens and the comparison of strengthened specimens with the URM brick walls and the pre-damaged specimens repaired by the epoxy material.

Table 4: General experimental results for Series II specimens.

\begin{tabular}{lccccc}
\hline & & \multicolumn{3}{c}{ Maximum strength } \\
\cline { 3 - 6 } & & Test number & Test result (MPa) & Average (MPa) & COV (\%) \\
\hline Damaged & D-AS & 1 & 2.51 & 2.29 & 8.5 \\
& & 2 & 2.12 & & \\
Non-damaged & ND-AS & 1 & 2.25 & & \\
& & 2 & 1.49 & 1.60 & 17.1 \\
& & 3 & 1.40 & & \\
& & & 1.91 & & 0.79 \\
\\
& URM & & & 1.22 & 32.2 \\
\hline
\end{tabular}




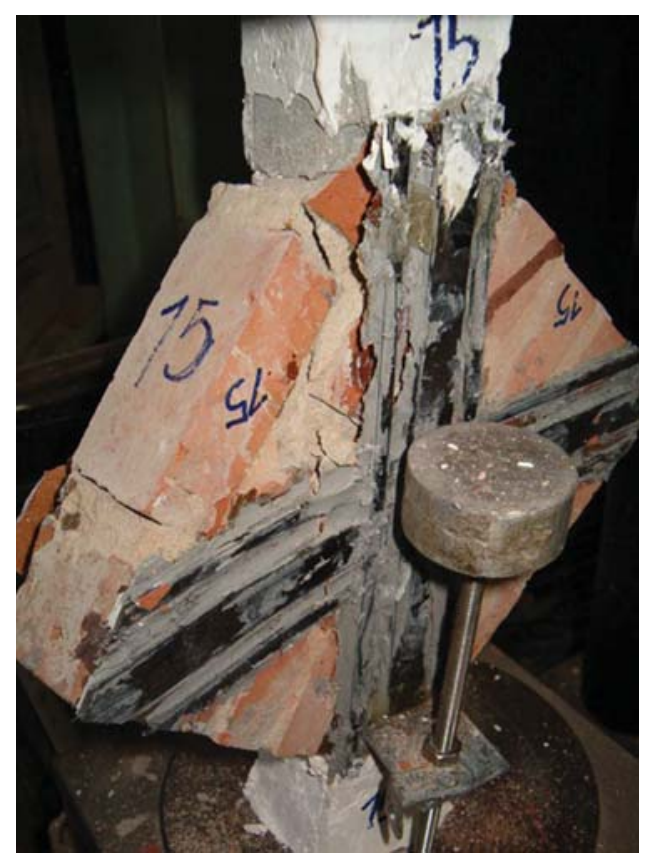

Figure 6: Series II failure mode.

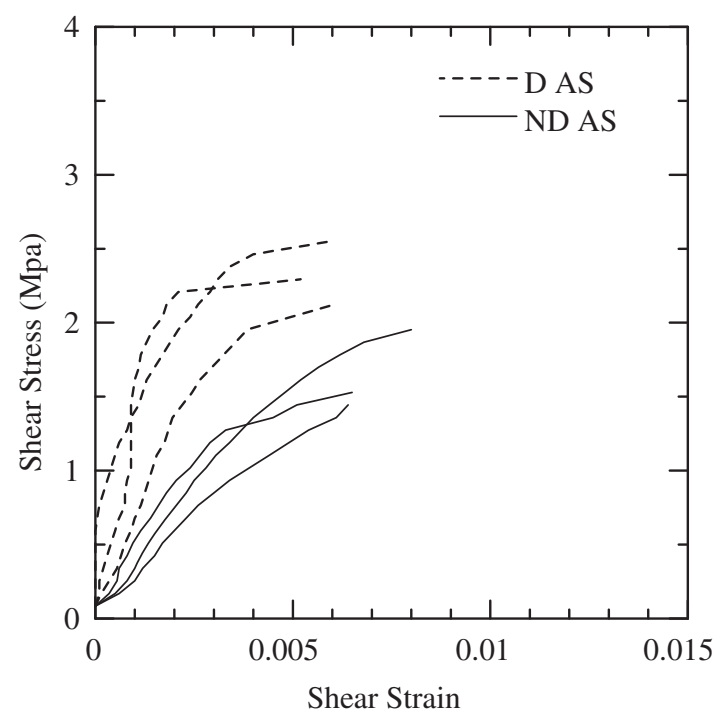

Figure 7: Series II shear stress-shear versus strain relation.

The specimens with highest fracture loading rating within Series III specimens are D-T, whereas the specimens featuring the lowest fracture loading rating are ND-T. The strengths of the specimens increase by two to three times compared with the URM walls, depending on the damage status. The shear stress-shear strain diagram is illustrated in Fig. 8. 
Table 5: General experimental results for Series III specimens.

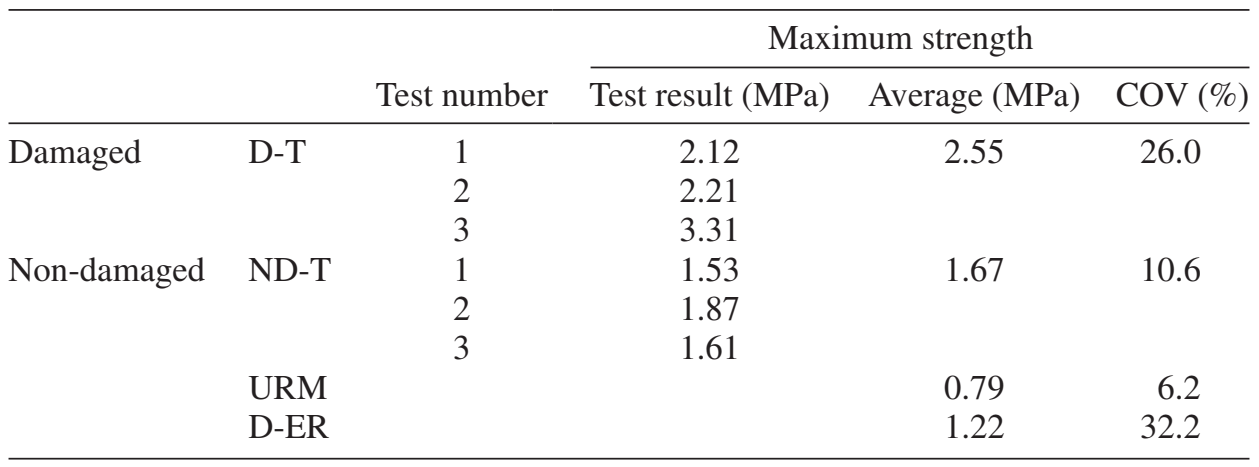

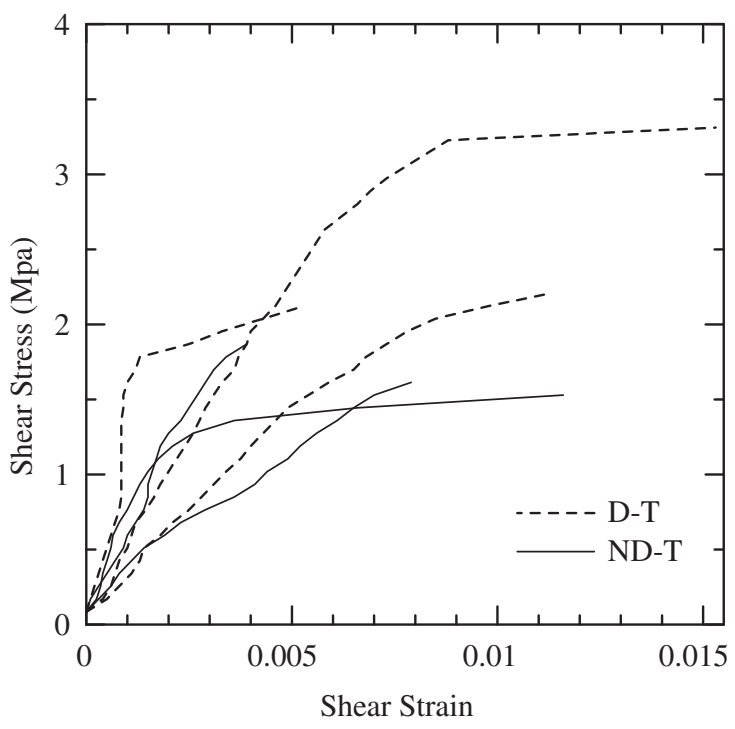

Figure 8: Series III shear stress-shear versus strain relation.

It is observed that, during the failure process, the adherences between FRP textile and the wall surfaces are extremely crucial. It is concluded that the failure is induced in the brick's internal structure. No fragmentation is observed in strengthened specimens whatsoever. As a result of the internal forces generated within brick wall specimens, they either collapse or the cracks are propagated in the bricks along the joints, which give rise to brittle fracture at failure.

As in the case for Series I specimens, the increases in the strengths of the brick wall specimens strengthened only on one side imply that such strengthening improves the specimens' behaviour. Irrespective of the type of strengthening, the application only on one side results in eccentricity due to the asymmetrical sectional geometry, resulting in premature failure. The typical failure mode of Series III specimens is illustrated in Fig. 9.

\subsection{Overall comparison of experimental results}

The brick wall specimens strengthened using CFRP textile perform better irrespective of whether pre-damaged or non-damaged specimens are used. According to the comparative results, the highest 


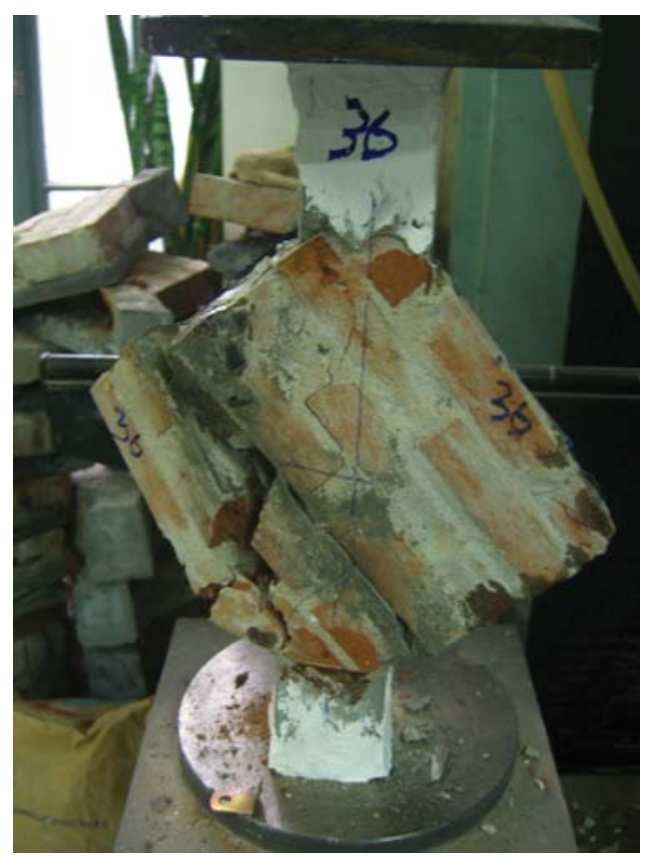

Figure 9: Series III failure mode.

fracture loading rating is achieved for D-T specimens, i.e. pre-damaged brick wall specimens strengthened by CFRP textile. The lowest failure loading rating is observed for ND-S brick masonry wall specimens, i.e. non-damaged specimens strengthened using laminated CFRP strips. With regard to the displacements, the improvements in Series III specimens are also better than in Series I and Series II specimens.

The strengths of Series II brick wall specimens turn out to be slightly higher than those in Series I. In case laminated CFRP is used, the apart-stripe form is suggested for showing better performance due to the application area extension. The maximum strength results for all experiments are illustrated in Fig. 10.

Affirmative effects of repair by the epoxy materials are observed in the comparative studies. When pre-loaded to induce the damage, the URM brick walls undergo failure along their weakest part upon fracture, i.e. in most cases along the compression diagonal of the wall. Brick wall specimens repaired using the epoxy materials exhibit higher strengths than URM brick walls prior to damage. This is in fact contrary to reasonable expectation that the non-damaged specimens would exhibit higher performance following strengthening. However, repairing with epoxy material causes significant increases in the strengths of these portions compared to the other portions of the specimens. Therefore, this process provides significant improvements in both failure and strain characteristics of the walls.

It can also be concluded that the average coefficient of variation for overall test results is $16.5 \%$, which shows the level of anisotropy and variability of masonry wall specimens and includes the experimental conditions, e.g. man-made specimens, temperature changes.

\section{CASE STUDY}

In Kayseri City, a site conversation area with seven stone houses built around 1900 were restorated by the Kayseri Metropolitan Municipality. Some of these are mansions and consist of three floors including a basement, a ground floor and a first floor. All buildings have a flat roof and were built 


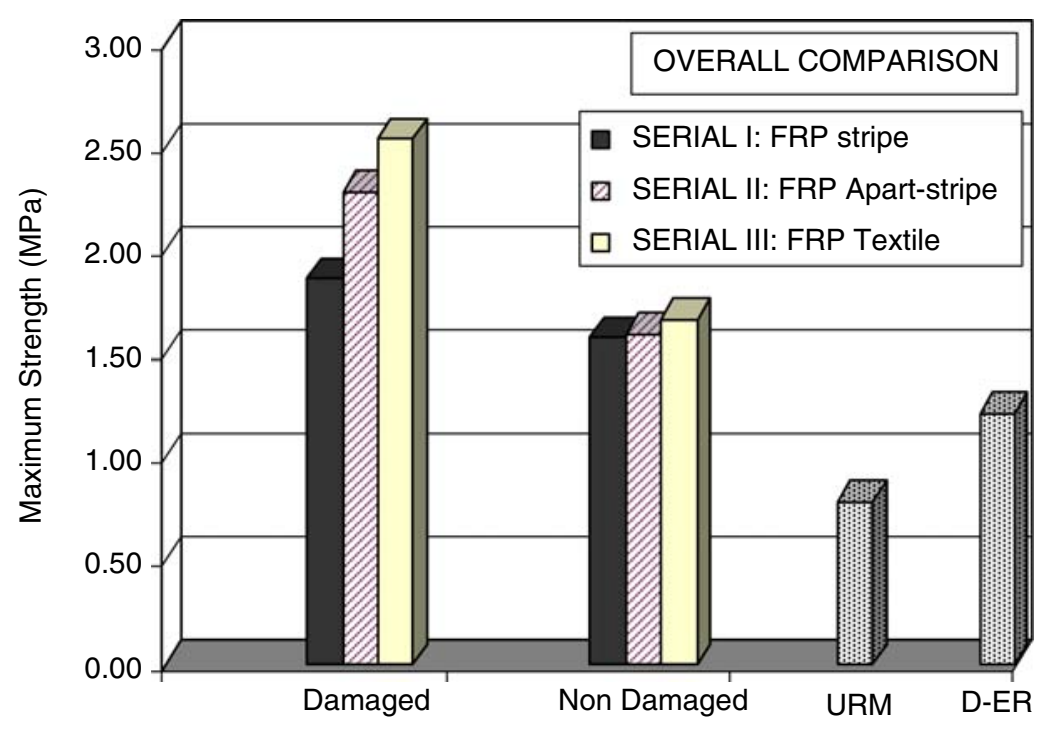

Figure 10: Overall comparison of experimental results.
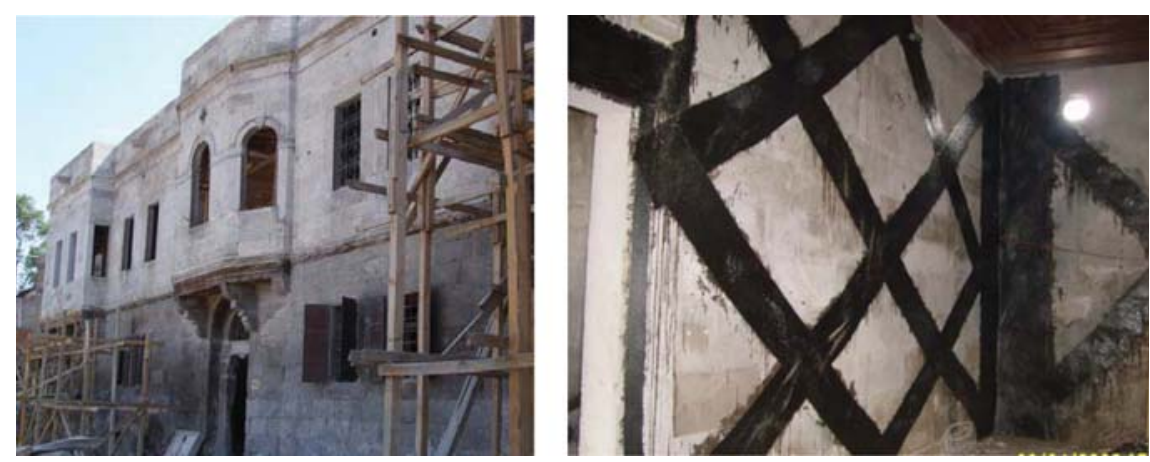

Figure 11: Front wall external view and CFRP application on the inner face.

contiguously. The historical buildings under preservation consisted of tokana (traditional kitchen), hamam (bath), köşk (kiosk), haremlik (woman section of the house), selamlık (men section of the house) and sofa (main hole) and represented many historical signs through their banisters, wood carvings and masonry ornaments.

For the repairing of cracks on masonry walls in the basement and upper floors, epoxy resin injection was used partially and for the inner walls CFRP was applied. CFRP application was accepted by the authority in charge for the inner walls and the inner sides of external walls as they were later covered with timber lining (Fig. 11).

The tensile cracks all over the buildings were repaired with epoxy injection. However, another serious problem is the insufficient mortar thickness of masonry walls which may cause excessive damage to the structure during a severe earthquake.

As it is not possible to strengthen the structure from the façade, the outer walls of the buildings were strengthened on the inner face and the inner walls were strengthened on both faces with 
bidirectional textile CFRP. Therefore, the masonry structural walls were protected from breaking into pieces and the strength was increased. Moreover, CFRP was also applied on the perpendicular intersecting points of inner walls which gives stronger connections at these intersections. In case the cracks are substantially wide, the strengthening was supplemented with reinforcing steel plates. Where wooden covering is not available, the cracks were repaired with epoxy resin but no CFRP was applied to preserve the original appearance of the heritage structure.

\section{CONCLUSIONS AND DISCUSSION}

In general, several observations are made with regard to repairing and strengthening of the masonry structural brick walls, which are remarkable enough to conduct further discussions following the experimental works on CFRP strengthening, using specific forms and types of FRP materials. As the structure in question is historical, FRP strengthening can be selected and used on one side of the walls so that the original façade is retained or covering the strengthened inner surface with a thin layer of the original stone or brick is still an option to keep the authentic look.

In brick wall specimens strengthened using laminated and textile CFRP materials, it is observed that the fragmentation of the brick wall specimens into pieces is effectively prevented as a result of wrapping obtained by the materials used for the purpose of the reinforcement. The URM brick walls usually collapse due to the formation of cracks along the loading axis or else in line with the joints or both the joints and the bricks. It is determined that strengthened brick wall specimens exhibit higher strengths and, in addition, they are not broken into pieces. Following strengthening, brick wall specimens undergo significant increases in their load-bearing capacities.

Although the strengthening is provided on one side of the brick wall specimens, the load-bearing capacities increased even though some eccentricity issues occurred. It should be recognized that the experiments are performed on single wall specimens but during a real application in a historical building the CFRP strengthening will be applied on opposite walls in plan which provides symmetrical behavior to the overall structure. The behaviour of the brick masonry wall specimens are closely related to the status, character and number of cracks formed during pre-loading of the specimens and the quantity of the epoxy material used to repair the cracks formed. Repair of the cracks generally formed along the compression diagonal, however, results in significant increases in the strengths of these portions compared to the other portions of the specimens. Therefore, it is likely that this is the main attribute which defines both the failure and the deformation behaviours of the specimens, rather than the type and quantity of the FRP used in strengthening. Another point to be emphasized here is that the sizes of the brick masonry wall specimens are small, whereas the repaired portion of the wall covers the majority of the wall surface area irrespective of how far the crack is observed. The bigger the size of the brick wall specimens, the lower the probability of observing such effects and therefore the epoxy materials will no longer play a significant role in strengthening.

Notwithstanding the lack of the tendency of the CFRP stripe and textile materials to separate from the surfaces of the brick wall specimens due to loss of adherence, in practice, it is highly recommended that the surface of the repaired brick walls are roughened prior to the application of FRP strengthening.

The highest strengths are obtained in CFRP textile strengthening applied on one side of the brick wall specimens, irrespective of whether pre-damaged and non-damaged specimens are used. The improvements obtained by strengthening using CFRP stripe are pretty much the same; however, CFRP textile strengthening provides better performance than CFRP strip. The highest performances are obtained for pre-damaged brick wall specimens strengthened with FRP textile. With regard to the higher cost of strengthening in the case of CFRP textile, it is observed that CFRP strip strengthening is more cost effective and that the apart-stripe form is especially suggested for better performance in cases involving application area extension. 
Environmental conditions affect resins and fibres used in FRP strengthening. The mechanical properties of some FRP systems, e.g. tensile strength, strain and elastic modulus, degrade under exposure to certain environments, such as salt water, chemicals, ultraviolet light, high temperatures, high humidity and freezing and thawing cycles. The material properties used in design should account for this degradation in accordance with the CFRP and adhesive material properties reported by manufacturers. An environmental reduction factor for various FRP systems and exposure conditions is given by several manufacturers and scientific studies. If applied properly, FRP strengthening systems appear to offer the same or improved life cycle cost estimates compared to other strengthening systems.

The amount of CFRP strengthening should be applied depending on the strengthening demand, the earthquake frequency, safety level and building importance factor which are given by the relevant codes. However, in case the structure is subjected to an unexpected effect and damage occurs, the damage can be repaired again and a new layer of CFRP can also be applied.

In all strengthening applications using CFRP, the brick wall specimens' performances improve significantly. In particular, the adjoining buildings allow strengthening only on one side of the facing walls. Strengthening of such walls even if it is possible only on one side will provide significant improvement. CFRP is an effective alternative material to be used in strengthening of masonry structures. The easiness and readiness of CFRP applications as well as its cost effectiveness and most of all the architectural integrity obtained when compared with strengthening using concrete and steel rendering, which causes significant change in the wall sections, are the major advantages of this alternative.

\section{ACKNOWLEDGMENTS}

The study presented here is sponsored by BASF-YKS Turkey. The authors acknowledge the financial support provided and the materials used in the experiments.

\section{REFERENCES}

[1] Ehsani, M.R., Saadatmanesh, H. \& Velazquez-Dimas, J.I., Behaviour of retrofitted URM walls under simulated earthquake loading. Journal of Composites for Construction, 3(3), pp. 134-142, 1999. doi:10.1061/(ASCE)1090-0268(1999)3:3(134)

[2] Albert, M.L., Elwi, A.E. \& Cheng, R.J.J., Strengthening of unreinforced masonry walls using FRPs. Journal of Composites for Construction, 5(2), pp. 170-178, 2001. doi:10.1061/(ASCE)1090-0268(2001)5:2(76)

[3] Tan, K.H. \& Patoary, M.K.H., Strengthening of masonry walls against out-of-plane loads using fibre-reinforced polymer reinforcement. Journal of Composites for Construction, 9(1), pp. 79-87, 2004. doi:10.1061/(ASCE)1090-0268(2004)8:1(79)

[4] Hamid, A.A., El-Akhakhni, W.W., Hakam, Z.H.R. \& Elgaaly, M., Behaviour of composite unreinforced masonry-fibre-reinforced polymer wall assemblages under in-plane loading. Journal of Composites for Construction, 9(1), pp. 73-83, 2005. doi:10.1061/(ASCE)1090-0268(2005)9:1(73)

[5] Krevaikas, T.D. \& Triantafillou, T.C., Masonry confinement with fibre-reinforced polymers. Journal of Composites for Construction, 9(2), pp. 128-135, 2005. doi:10.1061/(ASCE)1090$\underline{0268(2005) 9: 2(128)}$

[6] ElGawady, M.A., Lestuzzi, P. \& Badoux, M., Static cyclic response of masonry walls retrofitted with fiber-reinforced polymers. Journal of Composites for Construction, 11(1), pp. 50-61, 2007. doi:10.1061/(ASCE)1090-0268(2007)11:1(50)

[7] Onar, E., The experimental study on strengthening of structural brick masonry walls using carbon fibre-reinforced polymers, M.Sc. Thesis, Institute of Science and Technology, Istanbul Technical University, 2007.

[8] American Society for Testing and Materials (ASTM). Standard test method for diagonal tension (shear) in masonry assemblages. Annual book of ASTM standards, E 519-81, Vol. 04.05, 1981. 